\title{
What do the experts by experience tell us about 'what works' in high secure forensic inpatient hospital services?
}

\author{
James Tapp ${ }^{a *}$, Fiona Warren ${ }^{b}$, Chris Fife-Schaw ${ }^{b}$, Derek Perkins ${ }^{c}$ and Estelle \\ Moore $^{d}$ \\ ${ }^{a}$ Broadmoor Hospital, Centralised Groupwork Service, Newbury Therapy Unit, \\ Crowthorne, UK; 'bepartment of Psychology, University of Surrey, London, UK; \\ ${ }^{\mathrm{c}}$ Department of Psychology, Broadmoor Hospital, Crowthorne, UK; ${ }^{\mathrm{d} B r o a d m o o r}$ \\ Hospital, Centralised Groupwork Service, Crowthorne, UK
}

\begin{abstract}
The evidence base for 'what works' for patients detained in high secure hospitals has predominantly been established from a clinical perspective, with the voices of those at the centre of care, the expert by experience, absent. Neglecting this voice renders an important source of information for evidence-based practice inaccessible to outcome evaluators. Twelve high secure patients considered 'ready' to be discharged were interviewed to explore what in their view had helped or hindered their progress to this stage. Thematic analysis steps were applied to interviews and eight themes were generated that represented valued elements of high security: temporary suspension of responsibility, collaboration in care, learning from others, supportive alliances, specific interventions (medical and psy-chotherapeutic), a safe environment and opportunities for work. Narratives demonstrated the complementary and unique contribution of the patient experience in informing 'what works', and are discussed alongside existing theories relevant to promoting clinical change and risk reduction.
\end{abstract}

Keywords: high secure services; patient perspective; qualitative; thematic analysis; what works

\section{Introduction}

Investigations into 'what works' in high secure forensic hospitals have predominantly been conducted from a clinical perspective, where evaluation methods and markers of what constitutes success are determined by care providers (Tapp, Warren, Fife-Schaw, Perkins, \& Moore, 2011). This is consistent with the wider forensic mental health evidence base (Cohen \& Eastman, 2000). A perspective on the impact of high secure hospitals that is notably underrepre- sented is that of the expert by experience, the patient (Department of Health, 2001). With only a few exceptions, the tacit knowledge and experiences of patients in receipt of high secure inpatient treatment has not been included in

establishing its impact (Dell \& Robertson, 1988; Vartiainen, Vuorio, Halonen, \& Hakola, 1995). This is despite the inclusion of this voice in informing healthcare provision being advocated from both policy and evidence-based practice perspectives (Dixon-Woods, Fitzpatrick, \& Roberts, 2001; Marks, 2002). 
On a pragmatic level, the high secure inpatient perspective on the impact of treatment may be particularly valued where rigorous clinical evidence is absent, as is commonly reported in the forensic mental health arena (Blackburn, 2004; Quinsey, 1988; Rice \& Harris, 1997), and where the focus on outcomes is weighed on public interest, for example recidivism (Fitzpatrick et al., 2010). Such information might also contribute to both academic and public debates that re-emerge on the need for high secure inpatient facilities (Thomas, Dolan, \& Thornicroft, 2004). Where clinical evidence is available, investigating experiences of the person in receipt of treatment can also provide a complementary approach through triangulating evidence from multiple stakeholders (Malterud, 2001; Yardley \& Marks, 2004).

The patient perspective can also offer an in-depth understanding of "what works' in contexts where interventions may contain, or occur alongside, a host of therapeutic 'ingredients' that act independently or in concert towards the goal(s) of rehabilitation (Craig et al., 2008; Whitley \& Crawford, 2005). In high secure hospital settings, the task of improving the immediate and longer term clinical and functional status of patients is undertaken through a range of formal interventions, which may be complimentary, or possibly sometimes con- tradictory, in their rehabilitation aims (Lindqvist \& Skipworth, 2000). These can include therapeutic uses of the secure environment (Exworthy \& Gunn,

2003; Kennedy, 2002), and the development of supportive interpersonal relationships (therapeutic and communal) (Adshead, 2002). Whilst establishing clinical evidence through controlled trials is intended to circumvent the prob- lems of 'soft' boundaries between interventions, which can threaten the validity of findings (Wolff, 2001), these are reductionist and prescriptive for a specific task. This is evident in the case of reported reductions in reoffending following release, where there is limited information about the content of care that contributed to a positive long-term outcome for patients (Rice, Harris, Lang, \& Bell, 1990). To, therefore, understand the multiple or cumulative benefits of care, other approaches to gathering evidence are proposed (Blackburn, 2004; Green \& Britten, 1998; Whitley \& Crawford, 2005).

In order to capture an expert by experience viewpoint, individual interviews were conducted with inpatients at a UK high secure hospital who were ready to be discharged to explore perceptions of high secure experiences that had helped or hindered in progressing to this stage. On the basis that interventions in high security hospitals involve multiple elements, which vary in intensity over time, a holistic focus was taken to consider all potentially rehabilitative experiences of high secure hospital care (Lindqvist \& Skipworth, 2000). 


\section{Method}

Design

A qualitative interview study was used to investigate high secure inpatient per-spectives on experiences of treatment. Individual interviews were selected over alternative methods such as focus groups to permit a high level of focus on personal accounts of high secure experiences, which would be more difficult to attend to in a group context. Conducting individual interviews also reduces the potential for group conformity and censoring (Smithson, 2000).

Interview schedule

development

A general interview guide was developed using the 'puzzlement' approach (Lofland, 1971). This involved writing down points of interest related to the research question, which were then repeatedly organized into potential topics that were finally rephrased into broad questions (Appendix A). These provided prompts relevant and interesting to exploring the impact of high secure care. To focus discussions and limit restricted responses, a series of predetermined, open ended; neutral (non-leading); singular (not doublebarrelled) and clear questions were developed (Patton, 1990; Willig, 2001).

\section{Participants}

Participants were adult ( $>18$ years) male inpatients detained at a UK high secure hospital who were at the end of their individual care pathway and in the process of being discharged to a lower security hospital setting. Participants at this stage were selected on the basis that sufficient improvements in clinical and functional status had taken place such that the individual was considered by their clinical team to no longer require a high secure hospital bed.

\section{Inclusion criteria}

Male high secure inpatients at the end of individual care pathways, who were described as no longer requiring high security and who had been: (1) referred to/accepted by a lower secure hospital setting; (2) permission for discharge to a lower secure setting granted by the Ministry of Justice; and (3) approved discharge to prison following reduction in risk/remission of clinical symptoms.

\section{Exclusion criteria}

The study did not include inpatients who were not preparing for discharge or had been: (1) returned to prison due to non-engagement; (2) conditional/uncon- ditional discharge from Mental Health Review Tribunal; (3) repatriated to an equivalent high secure setting; (4) considered incapable of giving informed consent; and (5) identified as requiring an interpreter. 


\section{Sampling}

A non-probability purposive sampling method (Kuzel, 1992) was used for participant selection and recruitment to include participants with extensive experiences of high security, who had progressed to a position of being ready to leave. On the basis of the reported heterogeneity of forensic inpatients (Blackburn, 2004), clinical and forensic characteristics of participants are pre- sented alongside the distribution of characteristics for the hospital population to discuss the degree to which perspectives might be considered representative.

\section{Ethical considerations}

The study was reviewed and given a favourable opinion by the West London Research Ethics Committee and the University of Surrey Faculty of Arts and Human Sciences Ethics Committee.

\section{Participant recruitment}

Prospective participants were identified via discharge and patient administration system databases at the study site, which indicate pathway and discharge status for patients. Clinical team psychologists were also contacted to identify patients that met inclusion criteria. Responsible Clinicians of prospective participants were subsequently contacted to establish each individual's capacity to give informed consent and to request permission for them to be approached. On receiving written permission, prospective participants were individually approached and informed about the reason for being contacted and the purpose of the research, which was provided in a participant information sheet. Participants were given an opportunity to ask any question. Individuals choosing not to participate were given an opportunity to comment on reason(s) why, and then were no longer contacted. For individuals that opted into the research, formal written consent was taken and a time convenient to the participants was set to conduct individual interviews.

\section{Data collection}

Three pilot interviews were conducted to ensure that the research process (e.g. obtaining consent and research rationale) was feasible for the intended partici- pants and to determine the appropriateness and comprehensibility of questions and prompts for participants (Polit, Beck, \& Hungler, 2001). All individual interviews were conducted on participants' respective ward areas, in an interview room with sufficient privacy to ensure confidentiality. Interviews commenced with a briefing to restate the purpose of the study, issues of confidentiality and anonymity, and circumstances when these may be breached in accordance with professional guidelines (British Psychological Society, 
2009). Interviews were recorded using a security authorized digital recorder. 
Hand-written notes were also taken by the interviewer to formulate new questions, record responses that may be revisited to explore in depth and record any information that would indicate risks that might warrant breaches of confidentiality. Post-interview, participants were de-briefed and given the opportunity to ask any questions as well as discuss any issues of risk. Digital recordings were transcribed verbatim and subsequently deleted. A total of 12 interviews were conducted (see Table 1).

\section{Analysis}

Thematic analysis (TA) steps (Braun \& Clarke, 2006) were applied to the transcribed individual interviews to generate themes. The steps consisted of: data familiarization, generating initial codes, searching for themes, reviewing themes, providing definitions and names to themes. This analytic approach was informed by assumptions about the degree to which patients' perspectives would be grounded in forms of 'real' lived experience, and the level of objectivity-subjectivity with which these experiences could be reported and interpreted. These were viewed from a critical realist perspective (Bhaskar,

1975), which assumed that perceptions of high secure care that influence individual change reflect 'real' experiences, but a level of subjective interference may mediate the certainty with which these can be captured (Coyle \& Williams, 2000). In contrast to more interpretative qualitative approaches (e.g. discourse analysis and narrative analysis), TA can be applied to this set of assumptions.

In the absence of clearly articulated theories of change for this population (Hagell \& Bourke Dowling, 1999), and the holistic focus on 'what works', the interpretation of participant experiences was inductive, where analysis was based on the data, rather than a predetermined theoretical framework. However, to acknowledge the potential contributions of existing theories of rehabilitation in related arenas (Andrews \& Bonta, 2003), and to adhere to good TA practice (V. Clarke, personal communication, November 8, 2011), coherence of themes with relevant theoretical frameworks is discussed post-analysis. A reflective statement is also provided to discuss potential influences from the researcher, participant and social context on the conduct of the research and presented findings (Nightingale \& Cromby, 1999; Willig, 2001).

\section{Quality assessment}

To investigate the quality of the research procedures, criteria drawn from quality assessment guidelines for qualitative research methods were applied (Coffey, 2006; Lincoln \& Guba, 1985; Murphy, Dingwall, Greatbatch, Parker, \& Watson, 1998). Specifically, data collection methods are described to permit assessment of the credibility of conclusions drawn (Transparency); coding was independently conducted by a blind reviewer on an interview transcript 
and 
Table 1. Sample details.

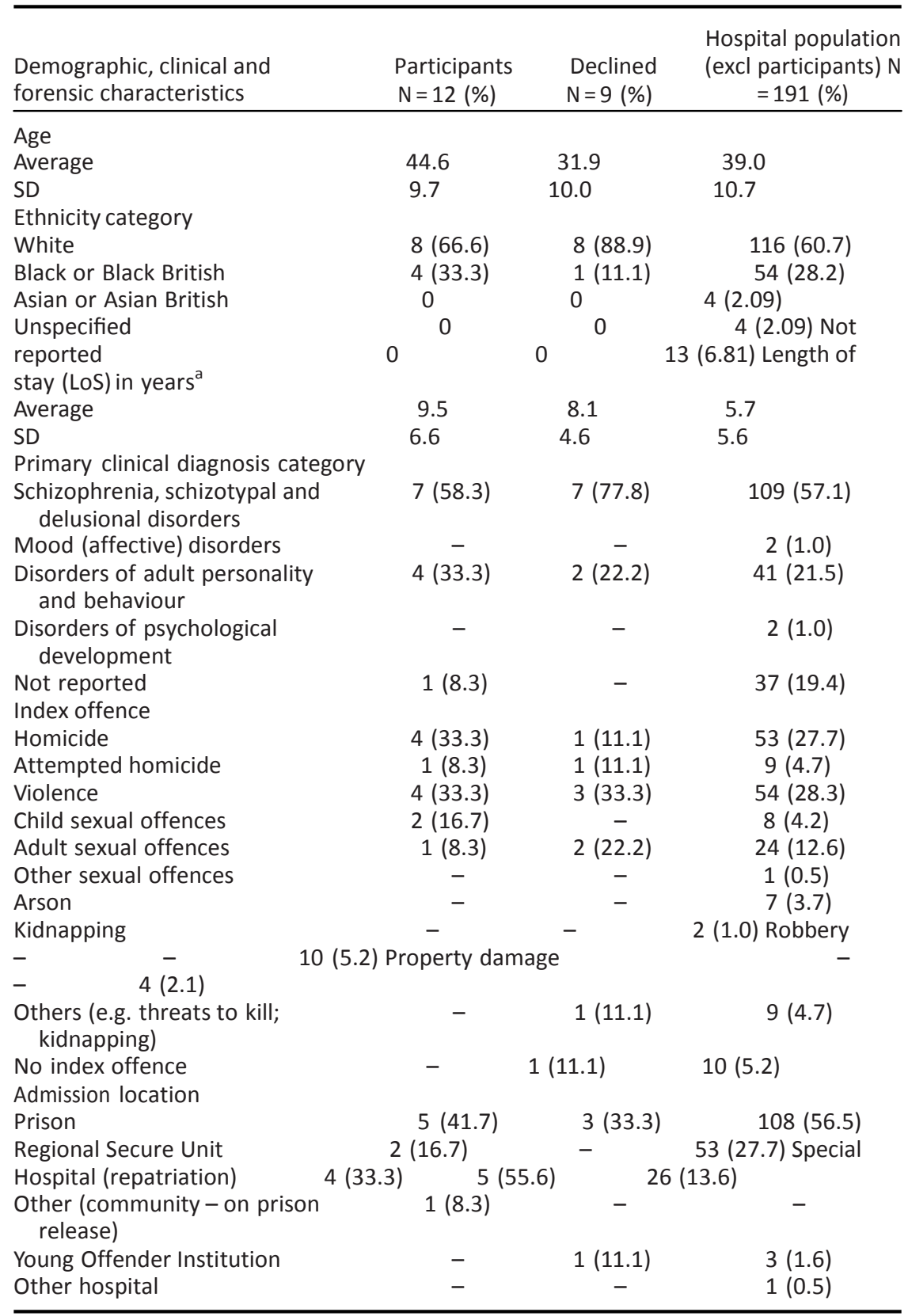

${ }^{a}$ LoS does not reflect total years in high secure services. 
divergent interpretations were discussed (Trustworthiness); participant sampling was examined against the wider hospital population to consider any absences of perspectives (Transferability); and a reflective statement is presented to consider potential influences on the conduct of the research (Reflexivity).

\section{Results}

A total of eight defined themes were generated from coded data. Themes repre- sented elements of high secure care that were experienced as having an impact on personal change. Supporting data include experiences, which had a positive impact on change, but also experiences that had a countertherapeutic effect, but still emphasized the importance of the element of care. Themes are described in turn; numbers presented in parentheses alongside quotes represent participants to indicate the coverage of data that support the theme (Braun \& Clarke, 2006; see Table 2).

\section{Theme 1: temporary suspension of responsibility}

The temporary suspension of individual responsibility through the process of being detained in high security provided respite from a less structured, at times destructive, lifestyle on the outside. Responsibility suspended whilst in high security, through enhanced (intensive) levels of care, equally managed presenting risks of harm to the person.

Table 2. Interview themes.

\begin{tabular}{ll}
\hline Themes $^{\text {a }}$ & Definition \\
\hline $\begin{array}{c}\text { Temporary suspension of } \\
\text { responsibility (7) }\end{array}$ & $\begin{array}{l}\text { Detention in high security and management in } \\
\text { intensive care units removes stressors and reduces } \\
\text { individual risk } \\
\text { A shared understanding and agreement of difficulties } \\
\text { and goals, and establishing a pathway out of high } \\
\text { security, fosters hope and provides motivation } \\
\text { Shared experiences and feedback from others promote an } \\
\text { awareness of difficulties and consequences }\end{array}$ \\
Learning from others (9) & $\begin{array}{l}\text { Psychotherapy interventions help in understanding, } \\
\text { managing, and resolving individual difficulties }\end{array}$ \\
Talking therapies (10) & $\begin{array}{l}\text { Mutual, trusting and empathic relationships provide } \\
\text { support throughout the process of recovery } \\
\text { Procedures for maintaining a safe and secure } \\
\text { environment minimize the risk of harm }\end{array}$ \\
Living in a non-toxic milieu & $\begin{array}{l}\text { Medical treatments manage active symptoms of } \\
\text { (7) }\end{array}$ \\
Medical treatments (9) & $\begin{array}{l}\text { Work serves as a means of structuring and occupying } \\
\text { time and social interaction, to maintain and promote } \\
\text { well-being }\end{array}$ \\
Opportunities for work (3) &
\end{tabular}

${ }^{a}$ Number in parentheses represents the number of participants whose data represented the theme. 
I actually said, that I am actually having a better quality of life in Broadmoor, than I actually have ever had in my life as a teenager or young child, and people couldn't understand that. (p. 8)

even though it's not quite like a monastery, it is because there are less distrac- tions, you don't have to worry about going shopping or, going here or going here, all things are all sorted, I can take time to think about more subtle things, which I wouldn't take notice of perhaps if I was in the community. (p. 10)

Suspending responsibility for too long whilst in hospital, for example on intensive care wards, was experienced as detrimental to well-being. Anxieties were also encountered as a result of detention through being detached from family.

a bit more contact with my family would have helped a bit I suppose ... on the phone like knowing they are well like it's just, makes a break from you know ... every time I call its like, phew. (p. 3)

Theme 2: collaboration in care

Collaboration in care was an essential element, which included: a shared (patient and professional) understanding of personal difficulties, being transparent and proactive in care pathway planning and promoting autonomy in care decisions. Respectively, these were valued in terms of: increasing insight into difficulties and how to support change; reducing the risk of hopelessness and setting achiev- able goals; fostering motivation and engagement.

so they [clinical team] worked it out, so, and since I worked out what my actual problem is, and they realised its not a mental illness, it's a personality disorder, it doesn't need medication, but it just needs me to have a better understanding that there are people around who is willing to look after me, and help me. (p. 2)

Conversely, where no choice or control over care was experienced, the value of care was lost, and shifts from having no control to losing control presented a heightened risk.

the thing is the problem with Broadmoor is we are asked to do things that we don't want to do ... and it takes away the value of doing it, it makes it unpleas- ant it becomes like a chore, which then brings on anxiety, then makes a person have more chance of becoming unwell. (p. 10)

the way the doctors was talking they was just you carry on the way you are going nowhere ... well if you have got no hope of going out, what does, I had no worries with harming people, what was the point in um, keeping control instead of losing control ... you ain't going nowhere. (p. 3) 


\section{Theme 3: learning from others}

Learning about the consequences of behaviour was reported to have been activated and fostered by interactions with peers, family and professionals. Sharing experiences with peers contributed to a greater understanding of personal difficulties and could also remove feelings of loneliness related suffering with serious problems. Feedback from others also promoted a sense of challenging individual thinking and an awareness of the consequences of actions.

so you listen to other people about what they are talking about and then you try to put some of that into your life about what you did and normally it gives you an understanding ... makes you aware there are other people like you, and other people got the same problems as you and you are not on your own. (p. 1)

sometimes when you hear other people talking about their self, you think hang on a minute I don't believe that at all ... and it makes you challenge the thoughts you have, its important. (p1)

people say that is out of order, you shouldn't have done that ... it makes me think I shouldn't have done it, it makes me think, re-think about it you know I just re-think the incident, so what happened, I just re-think to see whether he was right then in what he said ... (p. 11)

\section{Theme 4: talking therapies}

Talking therapies represent specific psychotherapy interventions (one to one or group), which provide an opportunity for exploring and understanding difficul- ties (increased insight) and developing coping and problem solving skills for managing these. The latter benefits make talking therapies distinctive from those experiences in learning from others, which also helps to gain an under-standing about personal experiences.

I think psychotherapy helped me to explain to myself, you know you talk about something, as you are talking you can negotiate better understanding for yourself. (p. 10)

I was quite an angry person, but I learnt a lot from self-talk (anger management), I still get angry, I lose it, and don't keep control of it, but, it's better than it was, I have been able to control it most of the time ... (p. 12)

\section{Theme 5: supportive alliances}

Supportive alliances represented trusted and caring relationships, old and new, between peers, family and professionals. These served a range of rehabilitative functions, which included: removing feelings of isolation; feeling cared for; 
promoting openness; emotional growth and challenging negative reactions towards 'others'.

I think it helps your cause if your family is involved in your care, ... It just shows you that someone cares for you, ... and you are not alone. (p. 9)

I actually had a girlfriend here, it was er, best girl I met all my life, so X was a big part of my growth and my, maturity ... feeling secure ... It makes you more, more valued, which is important for growth I think ... Not just physical growth, my emotional growth. (p. 10)

because people had knew what I done and still spoke to me, still approached me, still encouraged me and still supported me, it meant all the views I had or distorted views about I am going to be rejected, no one cares about me, um, all these distortions I had as a kid, didn't make sense anymore. (p. 8)

Barriers to building alliances and, therefore, reported benefits were also experienced.

I find it disgusting how this ward is because it been open now about 18 months and in that time I have had 7 primary nurses, 7 secondary nurses and about 8 back up nurses, you cannot build a relationship with staff like that, it's impossible ... I have a problem trusting people at the best of times, I am not going to be made a fool of, even though I am on me way. (p. 12)

Theme 6: maintaining a safe milieu

Safe management of the high secure environment was important to ensure the impacts of any crises were kept to a minimum.

in general those disruptions come in manageable sizes ... it is more manageable ... the person who attacked me, staff are restraining him and in seclusion, so it's not like it's going to be a huge great calamity. (p. 10)

Exposure to verbal, physical or emotional harm had clear implications for emotional well-being, and the potential toxicity from lapses in physical or procedural practices (e.g. accessing restricted items) could be equally detrimental.

I have been bullied in the past, um, by patients and um been mistreated a little bit by staff, during another time period, ... the experience what I find in top security hospitals are its quite um, it's not very easy to sort of explain, ... I have experienced anxiety. (p. 2) 
there was patients on there [ward] that were smoking dope and that, and I never connected my drug and alcohol problem to my criminal history ... I used to sit round smoking dope and all that, well of course my paranoia got worse. (p. 6)

\section{Theme 7: medical treatments}

Medication and electroconvulsive therapy (ECT) were valued medical interventions for putting an end to suffering from positive and negative symptoms of psychosis. Benefits were also reported for improvements in social functioning and engaging with other therapeutic activities.

At the moment I am on Clozapine and it is probably the best I have ever been. It makes me feel relaxed, my thinking is a bit slower, so I can think better, and I feel quite happy. (p. 9)

all I remember, I used to hear voices and see things, and I was paranoid and then after that [ECT], everything, all that had gone away ... it's a real godsend. (p. 7)

it [medication] still helped the therapies though, I could rationalize more ... I could see where other people were coming form, whereas before I thought they were just out to wind me up. (p. 5)

It was evident that establishing a steady medication regime took time and could be a difficult process before experiencing the benefits, with side effects being the inevitable cost. This included for ECT as well. These also had an adverse impact on functioning and engaging with other therapeutic activities.

well if you are asleep how can you go onto a group and concentrate, a group session if you, I mean I have fallen asleep in them. (p. 3)

I am not suicidal as I was so it [ECT] was a plus that way but it mucks your memory up ... that's what it has done to me, I used to be a lot sharper than what I am.

For others, medication was considered less a 'cure' and more a 'cover', with underlying problems remaining unresolved.

neuroleptics doesn't work for me, they have been more of a hindrance I would say ... they suppress the illness, um, they don't go to the root. (p. 10)

\section{Theme 8: opportunities for work}

The importance of work opportunities as a part of the recovery process in high security was voiced. The opportunity to occupy oneself from thoughts of being in Broadmoor, and respite from the ward environment, was helpful for individ- ual well-being. Work activities also provided a sense of improved selfefficacy and self-esteem through acquiring new skills and socializing with others. 
they took me down the gardens and that stopped me self-harming for quite a while, because you couldn't see Broadmoor from the garden ... if you turned round you actually couldn't see any of Broadmoor. (p. 6)

think working in the canteen gave me more confidence, and it made me feel that

I was worth something. (p. 1)

\section{Reflective statement}

A number of reflections were recorded throughout the process of exploring participants' experiences of care that warrant discussion alongside patient narratives. The interviewer being part of the high secure system and not independent may have mediated the freedom with which participants chose to discuss personal experiences. This was, particularly, as breaches of trust and

'over-reactions' from staff featured in discussions about experiencing setbacks in moving through high security to achieving the goal of discharge. The importance of self-presentation was also apparent in one interview, where the participant was being de-briefed on the broad common themes from completed interviewees who stated: 'them things you just mentioned, I should have mentioned myself but I think we have done a reasonable job'. This has been described as 'front stage' behaviour, where an impression is given to fit the context, in this example, wanting to be seen as having made the same contri- butions as others, and needs to be acknowledged in terms of the potential biases that can occur in individual interviews (Goffman, 1959). Perhaps connected with this was a discourse of risk often experienced across interviews, where participants referred to past experiences of 'getting into a bit of bother' and offences were often unspoken or similarly diluted 'no one is in here for nicking sweets'. Although it was also acknowledged by the interviewer that there was a potential reluctance to discuss sensitive topics such as risk, which may also mean these experiences which are central to the function of high security were only partly explored.

A further conscious influence from the interviewer concerned the emphasis on trying to provide an answer to the 'what works' question, potentially over-simplifying the complexity of change. As one interviewee put it, 'I think maybe, maybe the problem, where you are going wrong, I am not criticising you or anything ... you are looking for one particular clinching point, I don't think that exists'. The potential influence of the interviewer focus is further reflected in alternative interpretations from a researcher who coded a selected interview blind. Codings that described reported benefits of supporting vulnera- ble peers, which promoted a sense of individual responsibility and were linked with having an opportunity to 'make amends', provide an example of this. These were excluded in the presented themes, perceived as not being sufficient to constitute a theme, but perhaps highlight an important rehabilitative function of social support networks that work both ways, which is not represented. 


\section{Discussion}

Experiential information from the high secure service expert by experience can help in identifying valued elements of care that impact on individual change. Certain positive experiences corresponded to the clinical evidence for specific interventions, for example, the value of medication (specifically Clozapine) in managing symptoms or the benefits reported from talking therapies (Dalal, Larkin, Leese, \& Taylor, 1999). Accounts of experiences also provide original insights into elements of care, which can be substantiated by a degree of theoretical coherence. These elements reflect therapeutic uses of security, clinical approaches to care, valued alliances and the importance of keeping occupied. Patients can often narrate the complexity of the high secure hospital experience across these elements, emphasizing the importance of each, sometimes independently and sometimes interdependently, which has been voiced before (Vartiainen et al., 1995). Reported experiences also indicate the difficulty of balance and timing of interventions in a setting that can at times be incongruent with autonomy and self-support (Lindqvist \& Skipworth,

2000). The value of elements is as readily supported by experiences of what had worked, as well as what had not.

The rehabilitative gains from mutually trusted alliances with peers, professionals and family whilst in high security were numerous, and also represented an essential ingredient in other valued elements of care such as, learning from others and talking therapies. The importance of alliances resonates with the essential need for secure attachments, which can be absent in the lives of forensic patients with reported histories of separation, loss and emotional or physical abuse (Taylor, 1998). Secure attachments within and outside of the institution are proposed to increase individual capacity to identify and understand one's own difficulties and how these impact on others (Adshead,

2002). Trusted alliances were necessary to feel safe to discuss issues and also provided feedback as to the consequences that actions had on others. Safe alli- ances also served a more primal function in providing support and protection when feeling isolated or in moments of distress (Bowlby, 1969). Experiences, where care was not continuous due to constant changes in staff or a 'bad' rapport, were reported as examples of what works less well. This could run the risk of representing invalidating relationships or an absence of attachment security increasing a sense of loneliness and removing the opportunity for opening up about difficulties, which could be burdensome.

This interpretation of alliances draws parallels with the concepts of the therapeutic relationship (Horvath, 2001), but intentionally includes alliances outside of a specific psychotherapeutic space, and attachments that provided a longer term security (Schuengel \& van ljzendoorn, 2001). Core attributes of positive alliances with professionals were also differentiated from this. The core value of talking therapies was the fundamental benefit, and included being able to share perspectives on past experiences and problems with a 
professional, which improved understanding. This was best described as putt- ing pieces of a jigsaw puzzle together to make sense of oneself and others. A further jigsaw piece came from learning from others, particularly hearing expe- riences of peers, demonstrating the therapeutic value of universality (Whiteley,

1986; Yalom, 1995). Learning from others, peers, professionals and family, also emphasized the importance of social learning, which is advocated as a core 'what works' principle in changing antisocial behaviour (Andrews \& Bonta, 2003) and curative factor in group therapy (Yalom, 1995). Receiving clear feedback and communicating consequences were important for both mak- ing and evaluating change, which was down to the individual. Participants reported that without this dialogue, it was not possible to know whether progress had been made.

Despite concerns over being detained in Broadmoor, largely influenced by the stigma of its name and some of its residents, the anticipated toxicity of the environment did not necessarily match the lived experience. Whilst involuntary detention was difficult to accept, sometimes followed by an acting out (Norton

\& Dolan, 1995) or withdrawing response, with hindsight the temporary suspension of responsibility was perceived to be a necessary intervention. This has been similarly described in other (non-forensic) hospital settings as a 'necessary emergency brake' (Sibitz et al., 2011). During this time, it was important to balance the return of responsibility and have autonomy in care decisions. With no personal choice in care came the feeling of no control, which could lead to feeling and acting as a passive recipient of care or having no concerns over losing control, particularly if the clinical prognosis heard is a hopeless one. When calamities did occur, the knock-on effect of incidents was expectedly adverse; however, therapeutic uses of procedural security were experienced positively in managing these events, to maintain a healthy milieu (Kennedy, 2002). A complimentary element of high security in minimizing the impact of toxicity was the availability of opportunities, such as work, sports and social activities, which offered respite from thinking about being detained. This echoes previous statements about the significance of these experiences (Lockett, Secker, \& Grove, 2005; Vartiainen et al., 1995). However, the histori- cal pendulum swing for high secure services between security and therapy, experienced by many participants in their years of admission, raised references to the 'old days' which were seen as currently lost in terms of promoting social inclusion within the walls. The tilt towards a more security-driven service was a concern raised by some.

\section{Limitations}

Several limitations concerning how transferable the themes are warrant discus- sion. Excluding patients who are not ready for discharge in high security excludes a perspective on what does and does not work for patients that may have a significant number of complex difficulties that equates to 
lengthy admis- 
sions. Voices from certain high secure service representatives, based on over-simplified offence and mental health characteristics, were also absent and the sample consisted only of male patients (see Table 1). Concerning the credibility of interpretations made from individual experiences, no process of checking finalized themes with participants (membership validation) was conducted (Lincoln \& Guba, 1985). This was also complicated by the focus of the research, as the majority of participants were discharged at the time of analysis. Coding was conducted independently on a single interview and divergent inter- pretations were discussed, however, no further process to consider the credibil- ity of subsequent interpretations was done. Whilst potential theoretical contributions and overlap with existing patient narratives from what could be considered a comparable setting (e.g. Maltman, Stacey, \& Hamilton, 2008) lend support to presented themes, building on the limited research from this perspec- tive would be helpful in determining the confidence in presented findings.

\section{Conclusion}

Including the voice of the expert by experience in answering the 'what woks' question offers insights into the interventions and processes that are valued for progressing though high security to a stage of being ready to leave. In contrast to the existing evidence base for high secure forensic inpatient settings, essential elements from the patient perspective are predominantly identified as those, which represent the relational contexts around which the more formal high secure interventions occur. Maximizing the benefits from non-specific therapeutic processes, predominantly supportive alliances, would, therefore, seem one valid aim for services, given their core value.

Where experiences of change were attributed to 'specific' interventions, of

note, the markers for success from the patient perspective (feeling valued, increased confidence) are qualitatively different to the focused outcomes (alleviated clinical symptoms/problem reduction) from more rigorous research designs of existing evidence. This has an important implication for ensuring that all relevant and valued outcomes are included when investigating the effectiveness of interventions (e.g. Tonkin et al., 2012), as absence of these might lead to an incorrect conclusion of no benefit. This should also include potential iatrogenic effects, as reported in experiences of medication and ECT.

\section{Acknowledgements}

The authors would like to thank the study participants for giving up their time to share experiences during a period of transition.

\section{References}

Adshead, G. (2002). Three degrees of security: Attachment and forensic institutions. Criminal Behaviour \& Mental Health, 12, S31. 
Andrews, D.A., \& Bonta, J. (2003). The psychology of criminal conduct (3rd ed.).

Cincinnati, $\mathrm{OH}$ : Anderson.

Bhaskar, R. (1975). A realist theory of science. Leeds: Leeds Books.

Blackburn, R. (2004). 'What works' with mentally disordered offenders. Psychology, Crime \& Law, 10, 297-308.

Bowlby, J. (1969). Attachment and loss. Attachment (Vol. 1). New York, NY: Basic Books.

Braun, V., \& Clarke, V. (2006). Using thematic analysis in psychology. Qualitative Research in Psychology, 3, 77-101.

British Psychological Society. (2009). Code of ethics and conduct guidance published by the Ethics Committee of the British Psychological Society. Retrieved from http:// www.bps.org.uk/sites/default/files/documents/code_of_ethics_and_conduct.pdf

Coffey, M. (2006). Researching service user views in forensic mental health: A literature review. Journal of Forensic Psychiatry \& Psychology, 17, 73-107.

Cohen, A., \& Eastman, N. (2000). Needs assessment for mentally disordered offenders: Measurement of 'ability to benefit' and outcome. The British Journal of Psychiatry: The Journal of Mental Science, 177, 493-498.

Coyle, J., \& Williams, B. (2000). An exploration of the epistemological intricacies of using qualitative data to develop a quantitative measure of user views of health care. Journal of Advanced Nursing, 31, 1235-1243.

Craig, P., Dieppe, P., Macintyre, S., Michie, S., Nazareth, I., \& Petticrew, M. (2008).Developing and evaluating complex interventions: The new Medical Research Council guidance. BMJ (Clinical Research Edition), 337, a1655.

Dalal, B., Larkin, E., Leese, M., \& Taylor, P.J. (1999). Clozapine treatment of longstanding schizophrenia and serious violence: A two-year follow-up study of the first 50 patients treated with clozapine in Rampton high security hospital. Criminal Behaviour and Mental Health, 9, 168-178.

Dell, S., \& Robertson, G. (1988). Sentenced to hospital: Offenders in Broadmoor. New York, NY: Oxford University Press.

Department of Health. (2001). The expert patient: A new approach to chronic disease management for the 21st century. London: Department of Health.

Dixon-Woods, M., Fitzpatrick, R., \& Roberts, K. (2001). Including qualitative research in systematic reviews: Opportunities and problems. Journal of Evaluation in Clinical Practice, 7, 125-133.

Exworthy, T., \& Gunn, J. (2003). Taking another tilt at high secure hospitals: The Tilt Report and the consequences for secure psychiatric services. British Journal of Psychiatry, 182, 469-471.

Fitzpatrick, R., Chambers, J., Burns, T., Doll, H., Fazel, S., Jenkinson, C., ... Yiend, J. (2010). A systematic review of outcome measures used in forensic mental health research with consensus panel opinion. Health Technology Assessment, 14, 1-94.

Goffman, E. (1959). The presentation of self in everyday life. Garden City, NY: Doubleday Anchor Books.

Green, J., \& Britten, N. (1998). Qualitative research and evidence based medicine. BMJ (Clinical Research Edition), 316, 1230-1232.

Hagell, A., \& Bourke Dowling, S. (1999). Scoping review of literature on the health and care of mentally disordered offenders. York: NHS Centre for Reviews and Dissemination University of York.

Horvath, A.O. (2001). The therapeutic alliance: Concepts, research and training. Australian Psychologist, 36, 170-176.

Kennedy, H. (2002). Therapeutic uses of security: Mapping forensic mental health services by stratifying risk. Advances in Psychiatric Treatment, 8, 433-443. 
Kuzel, A.J. (1992).B.F. Crabtree \& W.L. Miller (Eds.), Doing qualitative research (pp.

31-44). Thousand Oaks, CA: Sage.

Lincoln, Y., \& Guba, E. (1985). Naturalistic inquiry. New York, NY: Sage.

Lindqvist, P., \& Skipworth, J. (2000). Evidence-based rehabilitation in forensic psychiatry. The British Journal of Psychiatry: The Journal of Mental Science, 176, 320-323.

Lockett, H., Secker, J., \& Grove, B. (2005). FST project participants' and their clinicians' perceptions of the impact of having access to work opportunities through the First Step Trust (FST) Project in Broadmoor. Retrieved from http://www.centreformentalhealth.org.uk/pdfs/first_step_trust_broadmoor_report.pdf

Lofland, J. (1971). Analysing social settings: A guide to qualitative observation and analysis. Belmont, CA: Wadsworth.

Malterud, K. (2001). Qualitative research: Standards, challenges, and guidelines. Lancet, 358, 483-488.

Maltman, L., Stacey, J., \& Hamilton, L. (2008). Peaks and troughs: An exploration of patient perspectives of dangerous and severe personality disorder assessment (Peaks Unit, Rampton Hospital). Personality and Mental Health, 2, 7-16.

Marks, D. (2002). Perspectives on evidence-based practice. Retrieved from http://www. nice.org.uk/aboutnice/whoweare/aboutthehda/evidencebase/publichealthevidences - teeringgroupproceedings/perspectives_on_evidence_based_practice.jsp

Murphy, E., Dingwall, R., Greatbatch, D., Parkēr, S., \& Watson, P. (1998). Qualitative research methods in health technology assessment: A review of the literature. Health Technology Assessment, 2, iii.

Nightingale, D.J., \& Cromby, J. (1999). Social constructionist psychology: A critical analysis of theory and practice. Buckingham: Open University Press.

Norton, K., \& Dolan, B. (1995). Acting out and the institutional response. Journal of Forensic Psychiatry, 6, 317-332.

Patton, M.Q. (1990). Qualitative evaluation and research methods (2nd ed.). Thousand Oaks, CA: Sage.

Polit, D.F., Beck, C.T., \& Hungler, B.P. (2001). Essentials of nursing research: Methods, appraisal and utilization (5 ed.). Philadelphia, PA: Lippincott Williams \& Wilkins.

Quinsey, V.L. (1988). Assessments of the treatability of forensic patients. Behavioral Sciences \& The Law, 6, 443-452.

Rice, M.E., \& Harris, G.T. (1997). The treatment of mentally disordered offenders. Psychology, Public Policy, and Law, 3, 126-183.

Rice, M.E., Harris, G.T., Lang, C., \& Bell, V. (1990). Recidivism among male insanity acquittees. Journal of Psychiatry \& Law, 18, 379-403.

Schuengel, C., \& van ljzendoorn, M.H. (2001). Attachment in mental health institutions: A critical review of assumptions, clinical implications, and research strategies. Attachment \& Human Development, 3, 304-323.

Sibitz, I., Scheutz, A., Lakeman, R., Schrank, B., Schaffer, M., \& Amering, M. (2011). Impact of coercive measures on life stories: Qualitative study. The British Journal of Psychiatry: The Journal of Mental Science, 199, 239-244.

Smithson, J. (2000). Using and analysing focus groups: Limitations and possibilities. International Journal of Social Research Methodology, 3, 103-119.

Tapp, J., Warren, F., Fife-Schaw, C.F.S., Perkins, D., \& Moore, E. (2011). A critical analysis of the clinical evidence base from high secure forensic inpatient services (PhD thesis). Surrey.

Taylor, P. (1998). Patients as intimate partners: Resolving a policy crisis. In C. Kaye. \& A. Franey (Eds.), Managing high security psychiatric care (pp. 136-154). London: Jessica Kingsley. 
Thomas, S., Dolan, M., \& Thornicroft, G. (2004). Re-visiting the need for High Security Psychiatric Hospitals in England. Journal of Forensic Psychiatry \& Psychology, 15, 197-207.

Tonkin, M., Howells, K., Ferguson, K., Clark, A., Newberry, M., \& Schalast, N. (2012). Lost in translation? Psychometric properties and construct validity of the English Essen Climate Evaluation Schema (EssenCES) social climate questionnaire Psychological Assessment, 24, 573-580.

Vartiainen, H., Vuorio, O., Halonen, P., \& Hakola, P. (1995). The patients' opinions about curative factors in involuntary treatment. Acta Psychiatrica Scandinavica, 91, 163-166.

Whiteley, J.S. (1986). Sociotherapy and psychotherapy in the treatment of personality disorder: Discussion paper. Journal of the Royal Society of Medicine, 79, 721-725.

Whitley, R., \& Crawford, M. (2005). Qualitative research in psychiatry. La recherché qualitative en psychiatrie, 50, 108-114.

Willig, C. (2001). Qualitative Research in Psychology: A Practical Guide to Theory and Method. Buckingham: OUP.

Wolff, N. (2001). Randomised trials of socially complex interventions: Promise or peril? Journal of Health Services Research \& Policy, 6, 123-126.

Yalom, I.D. (1995). The theory and practice of group psychotherapy (4th ed.). New York, NY: Basic Books.

Yardley, L., \& Marks, D.F. (2004). Introduction to research methods in clinical and health psychology. In L.Y.D.F. Marks (Ed.), Research methods for clinical and health psychology (pp. 1-20). London: Sage.

\section{Appendix A. Interview schedule}

Thank you for participating in an individual interview to discuss your experiences of high security. The interview is kept strictly confidential except if you discuss any issues that might indicate a risk of harm to yourself or others, in which event this information will need to be followed up with your clinical care team. If at any point during the interview you decide to no longer participate in the study, you can withdraw with no implications for your care provided in the hospital, and your data will be destroyed.

Topic guide:

What were your early impressions of arriving at this hospital?

Prompt: How did you feel?

What was your opinion about the hospital before arriving? What had you heard about the hospital?

Can you remember the first people you met on your arrival?

What can you remember about the staff / patients / environment when you arrived?

What made the greatest impact on you?

What are your impressions of the hospital now?

Prompt: What is your opinion about the hospital now?

If different, how has your opinion changed?

What has influenced your impressions about the hospital over your time here? Have any impressions remained the same?

Might these ever have changed?

What do you think high security has provided you with? 
Prompt: How do you feel now looking back over your time here?

What has it been like for you?

What is the difference between where you are now and when you

first arrived?

What influenced this?

Which high secure experiences have been important to you? How do you remember your interactions with staff?

How would you describe, in your own terms, your progress through high security?

What would you say have been the key experiences you have had?

Prompt: Which experiences would you say had been supportive towards your progress? In what way?

Can you recall any experiences that you feel may have hindered this progress, or slow it down?

What role have you played in being ready to move out of high security?

Prompt: How much involvement have you had in your care within the hospital?

What decisions have you made in relation to your

experiences? How have these influenced your progress? 